\title{
The Different Roles of Help-Seeking Personalities in Social Support Group Activity on E-Portfolio for Career Development
}

\author{
https://doi.org/10.3991/ijet.v14i02.8718
}

\author{
Suthanit Wetcho, Jaitip Na-Songkhla $\left({ }^{\bowtie}\right)$ \\ Chulalongkorn University, Bangkok, Thailand \\ Jaitip.n@g.chula.edu
}

\begin{abstract}
Social Support plays a crucial role between recipients and service providers. It is a strong contributor in reducing the level of uncertainty in a situation, in both relationships with one's own self, as well as relationships on other levels. It can also be used within a group activity system such as E-Portfolio development. One example of this being the support provided to learners who have reflected on their own experience during a period of transition. However, it is possible that some of the learners who participated in the social support group activity may not have been familiar with the community and may have acted differently, changing their help-seeking style within the group. This research used Activity theory as a tool to define the activity structure and aimed to focus on the working behavior among members of a social support group with different help-seeking personalities. The experiment also revealed the effects of Eportfolio development on self-efficacy skills in career-based decision-making, based on different help-seeking personalities using PretestPosttest. Nonequivalent Control Group design. Upper secondary school students in Thailand were used as the population in the research. Participants in this study were also students under Royal patronage in grade $11(\mathrm{n}=80)$ and there were students from each region of Thailand. These participants attended the guidance and preparation summer camp in collaboration with Chulalongkorn University. It is revealed by the findings that the statistically significant difference is at the level of .05 in Autonomous help-seeking learners and within the subgroup 3, which included Autonomous and Dependent help-seeking learners. The helpseeking personality working styles in the support group are discussed.
\end{abstract}

Keywords - Social activity, group support, e-portfolio, help-seeking, career development

\section{Introduction}

The importance of information and communication technology development, as well as career preparation for learners, was emphasized in the National Education Plan 2017-2036 of Thailand, issued by the Secretariat of the Council of Education [15]. In particular, it is important for high school students who are in adolescence (12-18 
years), meaning that they are rapidly developing in terms of the body, intelligence, emotion, society and personality. As a result, children of this age can make decisions and start thinking of adulthood and personal interest in their future career. One of the key points which is to be considered during transitional periods, concerning social aspects, is the perfect time to prepare a career plan. People of this age are required to make a decision on issues, for instance, when the right time to go to university is. [8]. An electronic portfolio (E-Portfolio), is one of the popular tools used to develop selfefficacy concerning career decisions. Students are provided with clear guidelines, allowing them to gather information and take advantage in order to make decisions about themselves, their education, and their careers. The aim of this is to help them to understand various roles in life. However, from a social perspective, each of processes in the e-portfolio, such as reflection and evaluation, consists of social interactions and relationships with others. Activity theory was defined by Engeström (1999) [6] as behavior that contributes towards society. Activity Theory also has many factors, both internal and external, like the environment in which help is being provided to and received from others. For instance, if positive interaction and support is being received from families, teachers and friends, this is known as Social Support. In this research, the different roles of help-seeking personalities are focused upon in social support group activity during E-Portfolio development. Activity Theory Framework was used by the researchers to further explore the different behaviors between learners who place reliance upon others, those who place reliance upon self-working, and those who take responsibility within groups. To identify the division of labor within social support groups, a redesigned model of Activity Theory Framework was used. Finally, this research revealed the effects that E-portfolio development can have on self-efficacy skills in career-based decision making, based on different help-seeking personalities.

Psychology in Behavioral Science plays an important role in the differences in behavior between each person, especially regarding personality traits which are expressed in differing situations. Recent research has been conducted with the purpose of predicting personality behavior across many aspects. However, behavior can change depending on context and situation, and these phenomena need to be explained at that precise moment in time. The way in which we take research into real-life settings helps us to understand these behaviors when they occur in real-life situations [13]. Social support is affected by the Help-seeking personality trait. Nadler [11] stated that an individual needs support and diverse kinds of help, which include Autonomous Help-seeking, Dependent help-seeking and Avoidance help-seeking. It is possible that some groups may work well under the support of others, or reliance on others. At the same time, another group may work well when seeking independence, or self-reliance. We should look to understand the differences in personality, such as help-seeking behavior. There are contexts which can be applied to these seeking behaviors, included are:

- Level of need

- Enabling factors like attitudes toward help seeking, previous help seeking, and aware

- Seeking help [9]. 


\subsection{Social support group}

Social support is the process of using both verbal and non-verbal communications in term of both perceived and actually received assistance and resource, it is done in order to reduce uncertainty in a situation [3]. Awareness and control of their own experiences are also promoted by these groups. Social support is an interesting issue, as it aids in the explanation of human relationships, both physical and mental. The value of social support is to find answers, for example, why do people seek support from others when they are experiencing stress in their lives? Why do we feel a need to support others? What is the system or is there a disorder in the interaction? The answer to these questions leads deeply into the development of quality in everyday human life. More commonly, social support is discussed when thinking about health, although it is categorized as a field of behavioral science. Overall, there are three situations and types of counseling related to social counseling and support, these take place during transitional periods in life, such as changing accommodation, changing place or level of education, divorce, a changing of jobs that results in disruption of life, and changing circumstances; for instance, loss of spouse, relocation or potential disagreements within the family. Other behaviors or characteristics can also affect this, including anger, lack of social skills, and deviant behavior. Three categories have been created by researchers when talking about social support, which are socioemotional aid, instrumental aid, and information aid [19].

Social support is widely recognized in the world of health and well-being [17]. When describing the nature of social phenomena for additional scope in educational contexts, researchers found that social support also pertained. Based on the study of relevant documents and research, the following definitions are applied by the Institute for Higher Education Policy (IHEP), the term "social support" is a strategy that fosters patronage, the strengthening of social networks, internal connections, a sense of ownership, self-confidence, and the building of motivation in academic achievements. Good relationships between personnel and strong networking between friends are both included in social support in an educational context. Family networks, and networks between both friends and school will encourage students to succeed in terms of academic performance [20]. Social support also helps to reduce problems, and as such, this is related to the development of self-efficacy skills. It can also lead to success in education and provides guidance throughout transitional periods, due to the use of group processes, expression, activities, and networking [16]

\subsection{Activity theory}

Activity Theory is an interdisciplinary framework. Tools, people, and history are all included in the study of this theory. Interaction and interpersonal relationships are some of the activities that can occur, and there are two categories into which characteristics of the theory of activity are classified, namely:

- The study of individual applications

- The study of the belief that the results are from individuals who are learning together, asking questions and testing each other in the activity system [6]. 
Additionally, the elements of activity theory were proposed by Engeström, and are:

- Subject or target group

- Objectives, for example, activities that occur

- Community, a large environment of the system of activities

- Mediating Artifacts, the tools of the activity

- A rule, the common agreement about the components

- The Division of Labor, both duty and responsibility

- Outcomes, which are the goals be to achieved. In Figure 1, the components of activity theory used in this research can be seen. Each member of the group represents a different role when concerning division of labor.

In addition, membership is divided by the Egan's skilled helper model into 4 components:

- The Client is provided with a consultation process. For the benefit of the counseling process, assistance will occur

- The Helper uses the benefit of the group process, which involves members playing both client and helper roles through listening, sharing, and giving feedback; or offering interesting alternative choices

- The Model makes the members feel valued and learns to take responsibility, and

- The Reality check, which is a member who is able to express sincerely and feel compassion for other members, and also offer a choice of career opportunities [21]. When working as a group in a community, Activity theory was used in this research as a descriptive tool so that the structure of an activity could be classified.

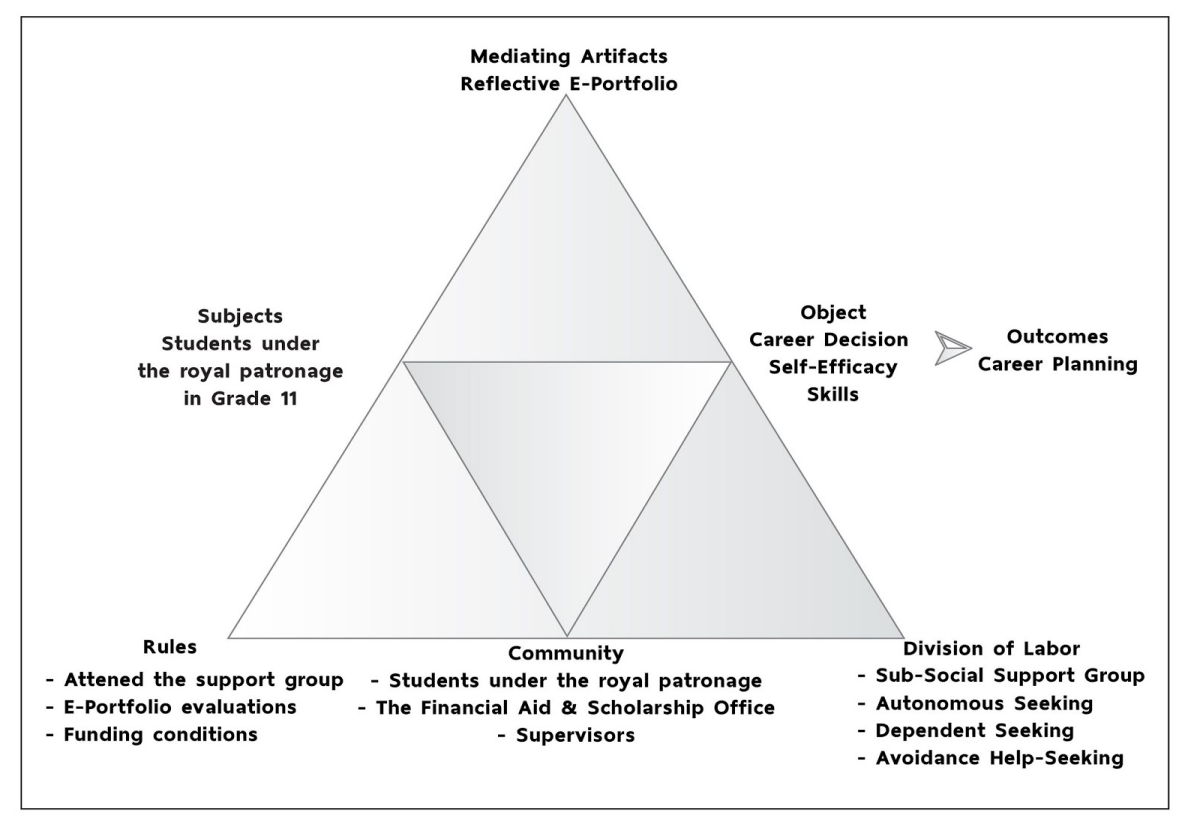

Fig. 1. The Activity structure division classified for this research 


\subsection{The reflective e-portfolio}

The Reflective E-portfolio is a showcase of the knowledge, skills, and attitudes of students, which can be used as an assessment tool to evaluate learners' progress and learning experience. Students' progress, critical and reflective writing are included to promote self-directed awareness of skills to support the personal development plans [5]. The skills developed by using portfolio included:

Communication skills: Involving the content of various subjects. Encouraging learners to bring their knowledge, views and opinions so that they can achieve the standard of learning

Acceptance of self and others: Recognition of strengths and weaknesses, then helping them to reflect on their own growth and social responsibility

Self-reflection: That helps learners learn from the mistakes and successes of their own actions

Critical thinking and problem solving: Understanding depth through critical thinking and problem solving to allow students to analyze, synthesize, and evaluate information for decision-making.

Value and ethics: Which include honesty, justice, equality, cooperation, selfacceptance, amongst others. Creating the value in making decisions in the real world

Conflict resolution: By understanding the context in which problems can be solved

The reflective e-portfolio: Is used as a mediating artifact in the activity system. Learners were responsible for creating and finishing their own E-portfolio, as well as taking advantage of others whilst in-group reflection, in addition to the peer evaluation that took place.

\section{$2 \quad$ Method}

\subsection{The design of the study}

The aim of this research was to examine self-efficacy skill levels when it came to career decision making, both before and after developing the reflective E-portfolio. This would be done in a social support group between different types of help-seeking personalities. The differences in working behavior between learners with varying helpseeking personalities were also stated in the research. In this research, the variables used were: The independent variables were: the use of social support groups, helpseeking personality patterns, and the E-portfolio activity based upon activity theory. The dependent variables were: self-efficacy skills in career-based decision making, specific research questions; which focused on the effects of reflective E-Portfolio development on self-efficacy skills in career-based decision making, and the personality traits that affect social support in a group of learners with different help-seeking personalities; working together through the portfolio development activities based upon activity theory. For this research, a Nonequivalent Control Groups PretestPosttest Design was used. The qualitative data collected from the learners' reflections 
on group work was also provided so that it could be used when carrying out this research.

\subsection{Participants}

Upper secondary school students in Thailand were used as the population in this research, and the participants in this study were students in grade 11, under the Royal patronage, whose ages ranged from 17-18 $(n=80)$. Furthermore, the participants originated from all regions of Thailand, and attended the guidance and preparation summer camp in collaboration with the Faculty of Education, Chulalongkorn University in March 2017. A Consent Form for students who participated in the activity was provided by the researchers in order to carry out data collection for the research. Subsequently, the purpose for the research was acknowledged by the participants and they agreed to provide relevant information throughout the course of the research voluntarily. The conditions of the research were as follows:

- The participants are in the scope of research

- The participants receive sufficient information about the research and procedure,

- The consent of the participants is voluntary

- The results of the questionnaire will not result in any negative effects or residuals that may harm the respondents, cause stress, anxiety, or any negative impact on their personal well-being.

Due to these requirements, researchers were obligated to keep strict confidentiality at all times. Samples from the demographics consisted of 80 participants, 26 males $(32.5 \%)$ and 54 females $(67.5 \%)$. The regions that the students were located in were as follows, 10 students (12.5\%) were from Central Thailand, $23(28.75 \%)$ were from Northern Thailand; 17 students were from the Northeast of Thailand (21.25\%), Eastern Thailand (14.5\%), and the South of Thailand (20\%).

\subsection{Instruments and procedure}

The instruments used in this research were a help-seeking personality questionnaire, the Career Decision Self-Efficacy scale (CDSE), and the Mahara EPortfolio System (free open software). The help-seeking personality questionnaire was adopted from Komissarouk and Nadler [10]. Consisting consisted of 14 questions, the questionnaire began with questions which let the participants' think about a problem they had faced, and still needed a solution for them to achieve self-goals. Then, the participants responded to the questionnaire by choosing the most appropriate approach to solving the problem. Each question consisted of seven grades, with scores ranging from -3 (strongly disagree) to 3 (strongly agree). Examples of the sample questions were: "I always ask for help in solving the problem", "Even if I deal with it myself", and "I always ask for help in resolving the problem before I try to solve the problem on my own". In developing this measure, the researchers reported an internal consistency with the Cronbach's alpha coefficient in the Dependent help-seeking personal- 
ity, Avoidant help-seeking and Autonomous help-seeking at .83, .74 and .84, respectively. It was also reported by the researchers that the reliability of the questionnaire for this research stood at .824 .

The Career Decision Self-Efficacy Scale (CDSE) (50 items) used in this study was adopted from the measurements of Taylor and Betz [2]. The rating Scale was made up of 5 levels of confidence, from 1 (not confident), to 5 (most confident). Score variations from 50 questions, then divided into to a total of 5 points, were used to assess the level of confidence in career based decision making. Following, are the meanings of each grade level, 1.0 to 2.5 means low confidence level, 2.5 to 3.5 means the level of confidence is moderate, 3.5 to 5.0 means the participant has a good level of confidence. The testing process was carried out by the researchers with 30 learners, and the reliability of this research was then reported using the Cronbach's alpha coefficient, which displayed a result of .966

During the first step, a questionnaire was distributed by the researchers on the three Help-Seeking styles, which were as follows; Dependent help-seeking, Avoidance help-seeking and Autonomous help-seeking personalities. Learners were then required to complete their self-efficacy skills assessment. After that, the learners were organized into experimental and control groups. The experimental group was made up of of 1 group (5-8 members, 6 groups), and the control group was composed of 40 members. Next, social learning activities were organized, so as to develop the reflective electronic portfolio over the course of a total of 12 sessions. Qualitative data was subsequently collected with the use of the observation form and learners' own reflections. Once the activity was complete, learners in both groups were asked to evaluate their own self-efficacy again, and the scores were taken from the test so that the data could be analyzed. Self-efficacy scores were compared by the researcher, comparisons were made between Autonomous help-seeking and Dependent help-seeking behavior types, together with Avoidance help-seeking in a social support group.

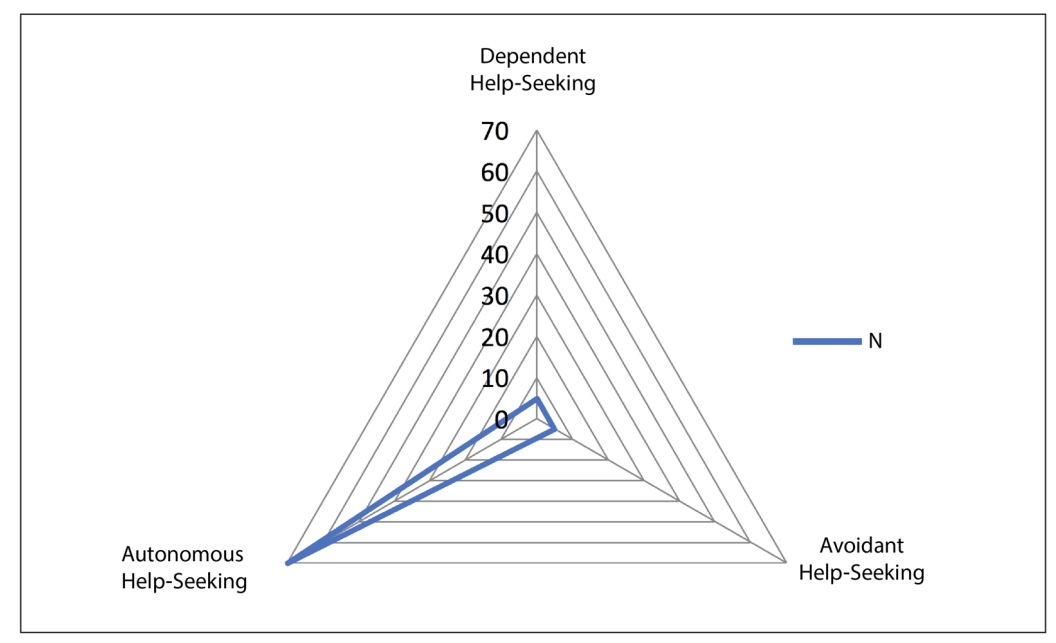

Fig. 2. The results of the questionnaire conducted using 80 samples. 
Based on the results of the data analysis, from the questionnaire on the three helpseeking styles in Figure 2 that had been distributed, it could be seen that there were 5 Dependent help-seeking students, 5 Avoidant help-seeking students and 70 students with Autonomous personalities. The Autonomous help-seeking style of the 70 people could not be divided into the three help-seeking styles in each group. However, as diverse patterns as was possible by the research conducted in the experimental group, which consisted of 5-7 students. This was based on probability as shown in Figure 3.
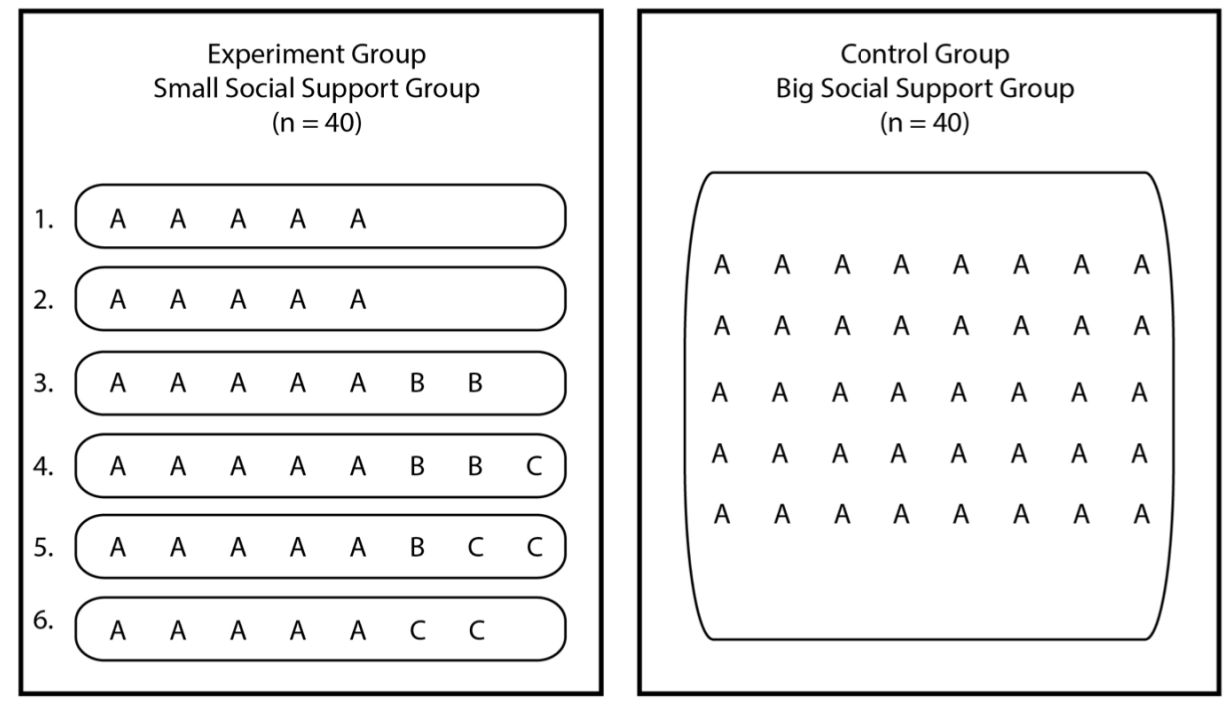

Fig. 3. Shows the actual situation in the research sample.

The personality symbols used in this research are as follows:

- The A symbol represents Autonomous Help-Seeking students.

- The B symbol for personality traits of Dependent Help-Seeking.

- The C symbol represents a person with an Avoidance Help-Seeking personality.

The different help-seeking behaviors of a personalized group of learners were focused on in this research, using the Activity Theory structure as a basis, while in the EPortfolio development stage. Then, the data was collected from the average score of self-efficacy skills in career-based decision making. Forty members of the experimental group were divided into three groups, these being: Autonomous, Dependent, and Avoidant help-seeking groups with 30,5 and 5 participants, respectively. In this section, the behavioral patterns of these participants were discussed. 


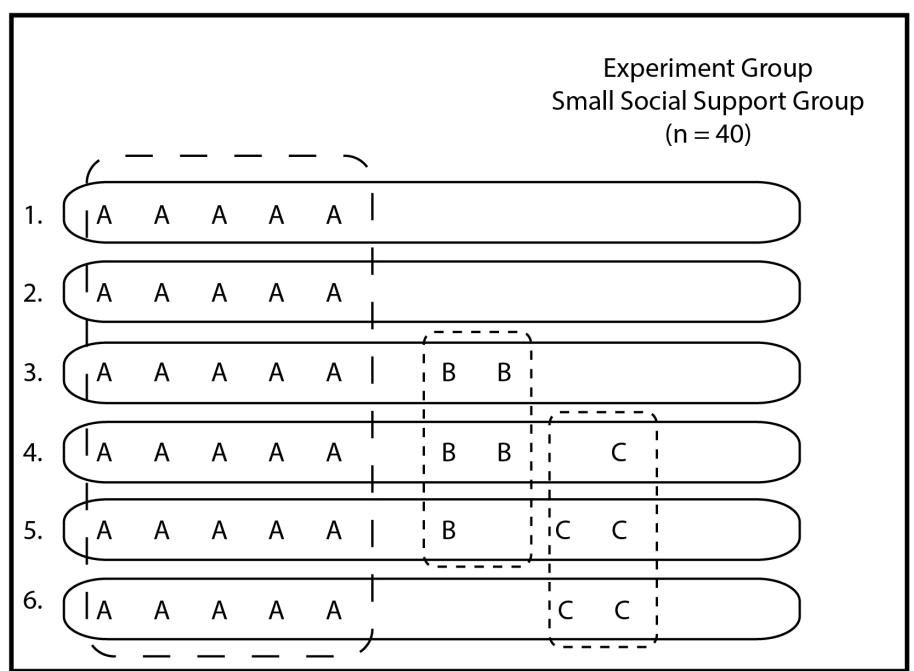

Fig. 4. Shows the experimental group used for analysis.

\section{Results and Discussion}

Issues with the discussion of this research included: The mean scores of the selfefficacy skills in career-based decision-making, which were obtained from the CDSE measurement of different personality groups in sub-social support groups. In addition to this, the behavior of members of the personality group from the reflective activities during the E-portfolio development stage was also considered.

Table 1. Levels of self-efficacy scores on career choice of different personalities in social support groups and subgroups.

\begin{tabular}{|l|c|c|c|c|c|}
\hline & N & M & SD & T & P \\
\hline Experiment Group & & & & & \\
\hline Autonomous & 30 & .57 & .69 & 4.54 & $.00^{*}$ \\
\hline Dependent and Avoidance & 10 & .656 & 1.17 & 1.76 & .11 \\
\hline
\end{tabular}
$* \mathrm{P}<.05$

The Paired-Sample T Test from IBM SPSS Statistical software was used when analyzing the data. It was found that there was a statistically significant difference in Autonomous help-seeking personalities at a significance level of .05 ( $\mathrm{Sig}=.00$ ). Though, we didn't find any statistically significant differences in the two other personality groups, Dependent help-seeking and Avoidance help-seeking, at a level of .05 $(\mathrm{Sig}=.11)$. 
Table 2. The mean scores of self-efficacy skills in career decision-making of the sub-groups.

\begin{tabular}{|l|c|c|c|c|c|}
\hline & N & M & SD & T & P \\
\hline Experiment & & & & & \\
\hline Pre-Post G1 & 5 & .74 & .72 & 2.30 & .08 \\
\hline Pre-Post G2 & 5 & .63 & .85 & 1.66 & .17 \\
\hline Pre-Post G3 & 7 & .63 & .52 & 2.21 & $.01^{*}$ \\
\hline Pre-Post G4 & 8 & .69 & .91 & 2.14 & .06 \\
\hline Pre-Post G5 & 8 & .51 & .79 & 1.82 & .11 \\
\hline Pre-Post G6 & 7 & .41 & .61 & 1.77 & .12 \\
\hline
\end{tabular}

$* \mathrm{P}<.05 \mathrm{G}$ stands for Group No.

There was, however, a statistically significant difference at the level of .05 observed in the social support group in subgroup 3 (Pre-Post G3). In this group, there were 5 Autonomous Help-Seeking students and 2 Dependent help-seeking, and while the average score differs from previous trials $(\mathrm{Sig}=.018)$, we have not found a significant difference at the level of .05 in any of the other groups. It can be seen that the average results of their self-efficacy skills, according to the personality of individual learners, were revealed in this data. In all three personality groups, Autonomous help-seeking personalities were found to be the highest scores after activity $(\mathrm{M}=4.025, \mathrm{SD}=.457)$, followed by the avoidance group $(\mathrm{M}=3.908, \mathrm{SD}=.574)$. Finally, the mean score of Dependent help-seeking personalities are the lowest $(\mathrm{M}=3,444, \mathrm{SD}=.757)$. Nevertheless, the scores of the three groups were shown to be higher average on average after attending social support activities than before participating in the activity.

\subsection{Reflective activity in group work}

Alongside the quantitative analysis, the qualitative data was collected from the group reflection sessions, based upon the Activity Theory structure, during which each learner had their own division of labor and followed the rules of the community. Working behavioral patterns were discovered during this process, these findings were taken from a series communications within groups and recorded in the group discussion session as follows:

Autonomous seeking (G1, G2): A general overview of acting in the group by doing their own work before could be observed, and there was mutual agreement in giving more help to others.

"Friends in the group help each other when they have finished their own" G1

"Some people do not talk to their friends" "Want to talk more" G1

"Maybe it's time to help a friend a little bit." "Need more public mind" G2

Group of students with autonomous help seeking and dependent help seeking (G3): In this group, there was an overview of helping other members when problems occurred and focusing more attention on group work.

"Everyone acts on their own and gives help when their friends have problems" G3

"Friends in the work group are slow and they should pay more attention to their friends" G3 
Autonomous help seeking and avoidance help seeking (G6): In this group, the participants demonstrated a good overview of their work, helping each other in order to solve common problems. Though, there were delays in reflection when solving problems, in addition to a need for more collaborative solutions overall.

"It is going good even though we have problems or obstacles at times, but we can help in resolving them in a quality way." G6

"Delay in solving problems" "Supporting to work as a team" G6

Autonomous help seeking, dependent help seeking and avoidance help-seeking (G4, G5): Here, students didn't reflect because they thought that they didn't have enough information regarding the work at hand, and felt that the group had unclear goals.

"They all can do tasks but the data is not enough to complete the file"

"Group is considered to be part of the goal, so we can do better" G4

"Some people still couldn't find the answer for themselves that's why they still do not reach the goal" G5 G5

"Some of the information may not be enough." G4 "The future goals are uncertain"

Displayed in the data analysis above are the mean scores and the significance level of self-efficacy perceptions on the career choices made by different personalities within the sub-social support groups. Using this data, we have summarized traceability information based on activity theory, as well as the behavior of the members of the personality groups during reflection-based activities. The summary produced from the recorded data is as listed: 1) Autonomous Seeking learners were inclined to find solutions to their problems independently. By doing their jobs successfully, they were able to participate in social support activities with different people. In turn, these people did not interfere with their work. They were also ready to help other members of their own group and show a good level of participation in social support groups. When compared with the other groups, self-efficacy skills in career-based decision making was higher, with the significant difference level of $.05(\mathrm{Sig}=.00)$, 2) Dependent Help-Seeking learners provided the lowest rates when they were working in the social support group compared with other personality groups. When it came to the development of career decision self-efficacy scores, they moved from a score of $(\mathrm{M}=2.496)$ to the mean score $(\mathrm{M}=3.444)$ after having participated in social support activities, and 3) Avoidant Help-Seeking learners tended to handle things by themselves, and in addition to this, did not like to play a dominant role in society, or their group. From the data, it was found that most of the group members own self-efficacy scores were already high $(M=3.544)$ but had still progressed to an average score of $(M=3.908)$ later on.

\section{Conclusion}

The behavior of help-seeking patterns is shown in the analysis of the data, including for Autonomous-seeking personalities, who are likely to provide behavioral support, and to help solve other peoples' problems in a similar way to their own. Moreover, the 
mean score of self-efficacy skills in career-based decision making is higher than that of the experimental group. Showing a significance level of $.05(\mathrm{Sig}=.00)$ when they were in the social support group. In the same vein, [18] it is evident that Autonomousseeking personalities will tend to rely on social support through information systems, and it is indicated that autonomous support is encouraging students to engage in the learning environment. Some examples of this is would be: having the opportunity to choose how you work, setting the rules together, and the freedom to work in order to achieve goals, namely choosing a group or setting a due date. Dependent seeking personalities were observed to be likely to seek help and rely on others in their society. For them, the roles and influences of others in society appear to be important. During the period in which this group was in the social support group, the mean score of selfefficacy skills in career-based decision making saw the lowest rates when compared to other personality groups, and after having participated in social support activities. The range of this score was from $(M=2,496)$ to the mean score $(M=3,444)$. Conversely, Avoidant-seeking personalities have a tendency to to handle things themselves and from the data analysis, it was discovered that most of the group members had their own self-efficacy scores when it came to career-based decision making, starting at ( $\mathrm{M}$ $=3.544)$ and progressing to the average score of $(\mathrm{M}=3.908)$. In line with these observations are [11], the self-reliant group, Autonomy help-seeking, is a group that seeks help from others, this could be applied when learning how to solve a problem manually and when helping people at the same level. Overall, the group looks for Dependency-oriented help-seeking personalities, or groups that want others to play a role in helping them, even if a problem occurs again in the same way. In addition, the Help Avoidance group can be described as a group of people who are primarily interested in finding answers by themselves, rather than trying to understand the work as a whole. This group do not need help from others because they believe their classmates have lower potential compared to their own, or they believe getting helps from others is not beneficial for themselves [7].

From the qualitative part of the study, which involved the participants doing their own work based upon the Activity Theory structure, the findings showed that the personality traits regarding help seeking in social support do not interfere with the work process of the learner, in both the individual and group functional processes. In accordance with the results of [4], a study of the metaphor of social cognitive theories, it was found that peer support variables positively influenced adolescent self-efficacy skills. Furthermore, [14] found that, in the low group, students are more likely to seek help from mediation tools using technology, especially on interactive forums and during office hours. While students in the high group tend opt for face-to-face methods when seeking help, peer support is the predictor of attitudes, and positively influences the pursuit of psychological support among adolescents [22]. Of all the above mentioned, it clearly shows that learners with different personality traits have the ability to work together within sub-social support groups regarding their ways of living. Still, in the study of help-seeking personalities, there are other factors to be considered, examples of these could be: gender, background, and experience. Differences in personality are found, in [10], to have a positive effect on attitudes when seeking help, such effects are: the difference between male and female participants, and open personality 
styles for new experiences. The effect this has on the nature of seeking help is positive. Ultimately, the gender, educational background, and personal experience of the participant getting help significantly contributes to the level of help that they seek [12].

\section{Suggestions for Further Study}

The researchers make the suggestion of using the research results from the social support group to be applied to promotion of learning, and the controlling of students' activities. This would be done by providing social support in three areas, including socioemotional aid, instrumental aid and information aid. While carrying out social activities, the structure of the group should be considered when creating social groups. Taking into account the different help-seeking personalities is important, as they can affect interaction and the level of function and participation in the social structure of the group. The researchers recommend that this would be done by organizing activities, like E-Portfolio development, and combining them together with social support activities. This could lead to the integration of social roles, involving socially beneficial behaviors in group members, such as teachers and fellow students. In conjunction with reflective processes, during the preparation of the portfolio, students will be encouraged to reflect on themselves, while there are other members providing support across various areas. It is suggested that future works on the social support group are to be developed using groups of students with different school levels. In future experiments, the sample of fifth-grade level learners should be expanded to other levels such as the 3rd grade, as this grade is close to the transition to upper-secondary school. Another recommended level would be the 6th Grade when learners are preparing to make the leap to higher education. Finally, at the graduate level in which participants would be making the transition from education to working environments.

\section{$6 \quad$ Limitations}

The results of this study were limited by the sample group however, the size of the sample in this experimental group has proven to be beneficial for sub-social support groups. The expansion of experimental and control groups into more diversity of personalities may create a clearer discussion to be had.

\section{Acknowledgement}

This research has been fully funded by the the 90 th anniversary of chulalongkorn university fund (Ratchadaphiseksomphot Endowment Fund). 


\section{References}

[1] Ash, L. E. (2000). Electronic student portfolios. IL, US: SkyLight Training and Publishing Inc.

[2] Betz, N. E., \& Taylor, K. M. (2012). Career Decision Self-Efficacy Scale (CDSE). www.mindgarden.com: Mind Garden, Inc.

[3] Chen, S. (2013). Social Support and Health: Theory, Research, and Practice with Diverse Populations. New York: Nova Science Publishers, Inc.

[4] Choi, B. Y., Park, H., Yang, E., Lee, S. K., Lee, Y., \& Lee, S. M. (2012). Understanding career decision self-efficacy: A meta-analytic approach. Journal of Career Development, 39(5). https://doi.org/10.1177/0894845311398042

[5] Domac, S., Anderson, E. S., \& Smith, R. (2016). Learning to be interprofessional through the use of reflective portfolios? Social Work Education, 35(5), 530-546. https://doi.org/10.1080/02615479.2016.1178717

[6] Engeström, Y., Miettinen, R., \& Punamaki, R.-L. (1999). Perspectives on Activity Theory. UK: Cambridge University Press. https://doi.org/10.1017/CBO9780511812774

[7] Golestaneh, S. M., \& Askari, F. (2013). Help-seeking or help avoidance: Important motivational, personality and metacognitive antecedent's role in help-seeking and help-avoidance between normal and gifted students. European Online Journal of Natural and Social Sciences, 2(3), 3403-3410.

[8] Hernandez-Martinez, P., Williams, J., Black, L., Davis, P., Pampaka, M., \& Wake, G. (2011). Students' views on their transition from school to college mathematics: rethinking 'transition' as an issue of identity. Research in Mathematics Education, 13(2), 119-130. https://doi.org/10.1080/14794802.2011.585824

[9] Johnson, E., \& Menna, R. (2017). Help seeking among adolescents in foster care: A qualitative study. Children and Youth Services Review, 76, 92-99. https://doi.org/10.1016/j.childyouth.2017.03.002

[10] Kakhnovets, R. (2011). Relationships among personality, expectations about counseling, and help-seeking attitudes. Journal of Counseling Development, 89, 11-19. https://doi.org/10.1002/j.1556-6678.2011.tb00056.x

[11] Komissarouk, S., \& Nadler, A. (2014). "I" seek autonomy; "We" rely on each other: selfconstrual and regulatory focus as determinants of autonomy and dependency-oriented helpseeking behavior. Personality and Social Psychology Bulletin, 1-13. https://doi.org/10.1177/0146167214524444

[12] Kumcagiz, H. (2013). Psychological help-seeking attitudes of helping professional candidates and factors influencing them. Academic Journals, 8(16), 1375-1382.

[13] Leary, M. R., \& Hoyle, R. H. (2009). Handbook of individual differences in social behavior. NY: A Division of Guilford Publications, Inc.

[14] Reeves, P. M., \& Sperling, R. A. (2015). A comparison of technologically mediated and face-to-face help-seeking sources. British Journal of Educational Psychology, 85, 570-584. https://doi.org/10.1111/bjep.12088

[15] Secretariat of the Council of Education. (2017). The National Education Plan 2017-2036 of Thailand. Bangkok: Office of the Education Council.

[16] Smith, E. (2010). The role of social supports and self-efficacy in college success. Institute for Higher Education Policy 1993-2015.

[17] Song, L., Son, J., \& Lin, N. (2012). Social network analysis. London: SAGE.

[18] Stefanou, C. R., Perencevich, K. C., DiCintio, M., \& Turner, J. C. (2004). Supporting autonomy in the classroom: Ways teachers encourage student decision making and ownership. Educational Psychologist, 39(3), 97-110. https://doi.org/10.1207/s15326985ep3902_2 
Paper-The Different Roles of Help Seeking Personalities in Social Support Group Activity...

[19] Thiots, P. A. (2011). Mechanisms linking social ties and support to physical and mental health. Journal of Health and Social Behavior, 52(2), 145-161. https://doi.org/10.1177/0022146510395592

[20] Vieno, A., Santinello, M., Pastore, M., \& Perkins, D. D. (2007). Social support, sense of community in school, and self-efficacy as resources during early adolescence: an integrative model. American Journal of Community Psychology, 39, 177-190. https://doi.org/10.1007/s10464-007-9095-2

[21] Wosket, V. (2008). Egan's Skilled Helper Model: Developments and Implications in Counselling: Taylor \& Francis.

[22] Yalçın, İ. (2016). The role of self-construal and perceived social support in prediction of attitudes toward seeking professional psychological help. Education and Science, 41(183), 339-349.

\section{Authors}

Suthanit Wetcho is a graduate student from Department of Educational Technology and Communications, Faculty of Education, Chulalongkorn University, Bangkok, Thailand

Jaitip Na-Songkhla is an associate professor and position in Head of Department of Educational Technology and Communications, Faculty of Education, Chulalongkorn University, Bangkok, Thailand

Article submitted 11 April 2018. Resubmitted 19 June and 30 September 2018. Final acceptance 19 December 2018. Final version published as submitted by the authors. 